\title{
Factors associated with gonorrhoea in men aware of being positive for HIV infection: case-control study
}

\author{
S T Sadiq, A J Copas, A M Johnson
}

Mortimer Market Centre, Camden and Islington Community NHS

Trust, London

WC1E 6AU

S T Sadiq,

specialist registrar in

genitourinary and

HIV medicine

Department of

Sexually

Transmitted

Diseases, Division of

Pathology and

Infectious Diseases,

University College

London Medical

School, London

WC1E $6 \mathrm{AU}$

AJ Copas,

research fellow in

statistics

A M Johnson,

professor of

epidemiology

Correspondence to:

Dr Sadiq

tsadi@msn.com

BMJ 1998;317:1052-3
Many of those attending genitourinary medicine clinics who are aware of being positive for HIV infection are diagnosed as having new episodes of sexually transmitted diseases, ${ }^{1}$ and evidence suggests that unsafe sexual behaviour has increased among homosexual men since the early 1990s. ${ }^{2}$ Despite this, public health initiatives to reduce HIV transmission among those infected with HIV have been lacking. Assuming that gonorrhoea is a marker for risk of transmission of HIV to others, ${ }^{3}$ we conducted a case-control study among men positive for HIV attending a genitourinary clinic for regular follow up, comparing those who acquired gonorrhoea with those who did not.

\section{Subjects, methods, and results}

All cases of urethral or rectal gonorrhoea occurring among men known to be HIV positive who attended a large London HIV clinic between April 1992 and March 1996 were identified from clinic and laboratory records. Two controls infected with HIV who did not have gonorrhoea but attended the routine clinic within one day of their matched case were selected randomly from computer generated lists. For every case and matched control a period of risk began at the first attendance at the clinic or at April 1992 (whichever was later) and ended on the date of diagnosis of gonorrhoea in the case. Data were collected from case notes. Statistical analysis took account of the matching and the differing periods of risk. Odds ratios were calculated using the conditional logistic regression function of STATA.

All 74 cases and 145 of the 148 controls were homosexual men. The mean (SD) age of cases at date of diagnosis of gonorrhoea was 30.9 (5.5) years and of controls 37.6 (7.8). Thirty five cases had urethral gonorrhoea alone, 35 had rectal gonorrhoea alone, and 4 had both. Only age at diagnosis of HIV infection (odds ratio 0.825 (95\% confidence interval 0.744 to 0.914 ) for every extra year) and log CD4 count (8.93 (2.91 to 27.24) for every increase by 1) were significantly associated with the acquisition of gonorrhoea in a forward stepwise model (table). These results may be partly explained by differential rates of attendance among patients and by patients attending other centres for genitourinary medicine when concerned about their sexual health.

\section{Comment}

The association between acquisition of gonorrhoea and younger age at diagnosis of HIV infection may imply a generational phenomenon or an association with age at recruitment to the study. The association with higher CD4 counts and asymptomatic disease is likely to reflect wellbeing. In our study patients infected with HIV were 10 times more likely than patients with AIDS to contract gonorrhoea. Antiretroviral treatment often results in a general improvement in wellbeing, and our findings suggest that its widespread use could lead to an increased prevalence of unsafe sex among patients infected with HIV. However, we could not test this hypothesis since such treatment became widespread after the period studied.

Patients without symptoms and those receiving current antiretroviral treatments have lower concentrations of HIV in semen, ${ }^{4}$ a probable major determinant of HIV infectivity. If such patients experience urethritis, particularly gonorrhoea, ${ }^{5}$ this may offset any reduction in semen HIV concentration.

Our patients seemed not to benefit from a single session with a health adviser immediately after they had been told that they were HIV positive, though clearly a benefit may exist (table). However, bias may arise if the offer or acceptance of counselling is associated with risk behaviour. Unfortunately, documentation in the case notes was not adequate to identify such a bias. This study shows that young men and those without symptoms may constitute a key group for research into and implementation of effective interventions among HIV positive men.

We thank Mauri-Moreno, computer coordinator at the Mortimer Market Centre, for identifying cases and controls from computer databases, and Lai Cheng, senior receptionist at the centre, for collecting and collating patient notes. We also thank Patricia Maguire for verifying the data collected and the entry of data for analysis.

Contributors: STS designed the study, discussed core ideas, designed study protocols, collected all data, participated in data analysis, and drafted and revised the paper for submission. AMJ

Univariate analysis of factors associated with acquisition of gonorrhoea after adjustment for periods of risk

\begin{tabular}{lc}
\begin{tabular}{l} 
Factor \\
\hline Age at HIV diagnosis (for every increase by 1 year)
\end{tabular} & $0.886(0.837$ to 0.937$)$ \\
\hline $\begin{array}{l}\text { Time since HIV diagnosis (for every increase by } 1 \\
\text { year) }\end{array}$ & $0.895(0.789$ to 1.016$)$ \\
\hline Place of HIV diagnosis: & 1 \\
\hline Study centre & $1.68(0.71$ to 4.00$)$ \\
\hline Other GUM clinic & $1.19(0.41$ to 3.48$)$ \\
\hline Non-GUM clinic & $0.76(0.33$ to 1.72$)$ \\
\hline Abroad & 1 \\
\hline Stage of HIV infection: & $0.44(0.22$ to 0.89$)$ \\
\hline A & $0.10(0.03$ to 0.29$)$ \\
\hline B & $7.80(2.95$ to 20.6$)$ \\
\hline C & \\
\hline Log CD4 count (for every increase by 1$)$ & 1 \\
\hline Counselling: & \\
\hline Before HIV test: & $0.68(0.28$ to 1.66$)$ \\
\hline No & 1 \\
\hline Yes & $1.03(0.40$ to 2.66$)$ \\
\hline After HIV result: & $0.79(0.16$ to 3.84$)$ \\
\hline No & \\
\hline Yes & \\
\hline After referral from another clinic: & \\
\hline No & \\
\hline Yes & \\
\hline
\end{tabular}

GUM=genitourinary medicine. 
had the idea for the study, discussed core ideas, advised on the design of the study, contributed to writing the paper, and edited the paper. AJS advised on the design of the study, was responsible for data analysis, and contributed to writing the paper. Patrick French was involved in initiating the study and advised on its design. Judith Stephenson advised on the study design. STS and AJS are the guarantors for the study.

Funding: No external funding.

Conflict of interest: None.

1 Catchpole MA, Mercey DE, Nicoll A, Rogers PA, Simms I, Newham J, et al. Continuing transmission of sexually transmitted diseases among patients infected with HIV-1 attending genitourinary medicine clinics in England and Wales. BMJ 1996;312:539-42.

2 Expert Group. Report. State of the epidemic 1994. Communicable Disease Report Review 1996;6:1.

3 Evans BG, Catchpole MA, Heptonstall J, Mortimer JY, McCarrigle CA, Nicoll AG, et al. Sexually transmitted diseases and HIV-1 infection among homosexual men in England and Wales. BMJ 1993;306:426-8.

4 Vernazza P, Gilliam BL, Dyer J, Fiscus SA, Eron JJ, Frank AC, et al. Quantification of HIV in semen: correlation with antiviral treatment and immune status. AIDS 1997;11:987-93.

5 Cohen M, Hoffman IF, Royce RA, Kazembe P, Dyer JR, Daly CC, et al Reduction of concentration of HIV-1 in semen after treatment of urethritis: implications for prevention of sexual transmission of HIV-1. Lancet 1997;349:1868-73.

(Accepted 24 February 1998)

\section{Science commentary: Vaginal viricides-another way to tackle HIV transmission}

Apart from persuading men to use condoms, women may also be able to protect themselves from contracting HIV and other sexually transmitted diseases by using vaginal viricides. In countries where HIV and other sexually transmitted diseases are prevalent but women want to become pregnant, viricides would offer a distinct advantage over condoms because they offer protection against diseases but still allow conception.

Viricides come as gels, creams, films, and foams, and two of the more promising viricidal compounds being tested are dextrin sulphate and nonoxinol 9 Dextrin sulphate stops HIV entering and infecting target cells by coating them. Nonoxinol 9 is the active ingredient in most spermicides and kills the virus by destroying its fatty outer coat. A third viricidal agent being tested is PRO 2000, which is a derivative of sulphonic acid. PRO 2000 blocks gp120 (one of the HIV viral envelope proteins), which stops the virus binding to CD4 receptors on target lympho- cytes.

In 1996 British women who were not sexually active and were at low risk of HIV infection took part in a safety trial of nonoxinol 9 , administered in the form of a gel. At the dose used-the standard spermicidal dose-the researchers discovered that it could cause irritation and inflammation of the vaginal mucosa. This would obviously increase the risk of pathogens invading the genital tract. A Belgian study and a study of Kenyan prostitutes which used lower doses of nonoxinol 9 found minimal destruction of epithelial cells. On the basis of these trials, an efficacy trial is now under way in Africa and Thailand using nonoxinol 9 at the lower dose. The main outcome measure will be the transmission of HIV from men to women.

Both dextrin sulphate and PRO 2000 have proved safe and acceptable in studies of healthy women, and they are being tested further in placebo controlled trials in sexually active women at low risk of HIV infection. If both the women and their partners can tolerate these substances, researchers plan to carry out efficacy trials in Uganda and the Ivory Coast.

Abi Berger, science editor, BMJ

\section{A memorable patient \\ An oldfashioned miracle}

A patient developed chest pains at home on Easter Friday; his wife suspected that he was having a heart attack and drove him to the nearest accident and emergency department in their own car. During the short journey, the patient lost consciousness and became cyanosed. On arrival at the hospital he was found to be in cardiac arrest. He was successfully resuscitated and then transferred to the intensive care ward where he was sedated and ventilated overnight.

He had a stable night and the following morning sedation was stopped with a view to extubation. Shortly afterwards he had several grand mal convulsions and so was resedated. I interviewed the patient's wife and warned her that her husband may have sustained serious hypoxic brain damage during his cardiac arrest. She told me that both she and her husband were committed Christians and that she would pray for his recovery.

The next morning (Easter Sunday) I arrived on the intensive care unit to find the patient being extubated by the anaesthetic registrar-during the night the patient's level of consciousness had improved and he was now indicating that the endotracheal tube was irritating him. Following extubation he seemed to be neurologically intact.
The patient's wife was waiting to see me, but perhaps something in my manner belied that I had good news because, before I could say anything, she told me that she was confident that her husband would make a full recovery-she had spent all night at a prayer vigil and was convinced that his recovery would be complete.

Since then, I have seen several recoveries on the intensive care unit which could be described as miraculous, but none with such wonderful timing.

T Kirkpatrick, consultant anaesthetist, Doncaster

We welcome articles up to 600 words on topics such as A memorable patient, A paper that changed my practice, My most unfortunate mistake, or any other piece conveying instruction, pathos, or humour. If possible the article should be supplied on a disk. Permission is needed from the patient or a relative if an identifiable patient is referred to. We also welcome contributions for "Endpieces," consisting of quotations of up to 80 words (but most are considerably shorter) from any source, ancient or modern, which have appealed to the reader. 